John Carroll University

Carroll Collected

2020

\title{
A Case Studies Approach to Teaching Introductory Physics
}

Gregory A. DiLisi

Alison Chaney*

Stella McLean*

Richard Rarick

Follow this and additional works at: https://collected.jcu.edu/fac_bib_2020

Part of the Physics Commons 


\section{A Case Studies Approach to Teaching Introductory Physics}

$\mathrm{O}$ ver the past several years, we have contributed several articles to TPT that focused on a forensics-style reexamination of historical events. In each article, we presented a case study as a pedagogy for teaching topics from introductory-level physics courses. Recently, we assembled our prior work into a series of "MythBusters"-style modules for pre-service teachers (PSTs). The goal of these modules is to widen the pedagogical viewpoint of the PSTs by exposing them to case studies as a means of teaching physics, problem solving, and critical thinking. In this article, we describe the design and rationale of our modules while providing anecdotal commentary from a cohort of PSTs who trial tested them. We identify several unique teaching opportunities that we share with readers of $T P T$.

\section{Design}

The pedagogical utility of case studies is a growing and well-researched area of physics education. In addition to reexamining historical events, case studies can incorporate the reverse engineering of products or the building of prototypes of newly conceived devices. While lumping these formats together is somewhat problematic since each has its advantages/ disadvantages and addresses different types of learning outcomes, we provide some references to readers of TPT so they can decide whether or not to implement these methods into their own courses. ${ }^{1-5}$ For example, the University at Buffalo, with support of the National Science Foundation, hosts the National Center for Case Study Teaching in Science. ${ }^{1}$ The center's site contains a searchable database of over 750 peer-reviewed case studies, encompassing all areas of science and engineering. Next, readers may find the guidelines presented by APS and AAPT as a way of structuring case studies for achieving their recommended student learning outcomes. ${ }^{5}$ Finally, APS's Forum on Education provides a nice summary of the rationale and benefits of using case studies in the introductory physics classroom. ${ }^{6}$

Combining best practices from the literature with the lessons learned from our prior work, we identified six advantages of using case studies as a pedagogical approach to teaching. As a result, six modules were designed and trial tested in an interdisciplinary science course for PSTs that addresses both content and methods. We did not design the modules to follow any particular curriculum of content; instead, we designed our modules with an emphasis on pedagogy. Our goal was simply to introduce PSTs to the use of case studies as a powerful teaching pedagogy and to afford them the opportunity to experience case studies firsthand. A specific case study from one of our prior TPT articles, in which physics was used to analyze a historical event, was chosen to showcase each of the six advantages-although we emphasized to the PSTs that each chosen case study could be used to highlight any of the identified advantages. We direct readers of TPT to our prior articles for detailed discussions of the specific rationales, laboratory exercises, and data analyses associated with each case study (Fig. 1). These articles, along with background information, additional readings, and classroom presentations, were compiled to form a manual for the modules. The format of each module alternated between seminar-style discussions and laboratory activities. To start, we asked PSTs to read the relevant $T P T$ article before class. Then, during the seminar portion of class, we reviewed the background information and used excerpts from eyewitness accounts, newsreel footage, and audio clips to authentically portray the event. PSTs were then divided into teams of four and moved to the laboratory where, in the spirit of the popular show "MythBusters," they tested leading (sometimes competing) theories posited by scientists and historians to explain why the event occurred. Each team performed the laboratory activity, as opposed to watching a single whole-class demonstration. The small team structure was crucial to the success of our modules since an unplanned benefit ensued from this socialization-an esprit de corps emerged among members of each team while friendly competitions pervaded the laboratory to see what groups could solve each session's historical debate. The drive to resolve each module's historical debate was palpable. Teams concluded the laboratory portion of each module by using problem-solving techniques to understand and interpret the underlying physics of the event. Finally, PSTs returned to the seminar room where we discussed results and polled workgroups in an effort to reach consensus in resolving the case study's historical debate. The advantages, which were highlighted in the modules and the accompanying case studies, are summarized below.

\section{Advantages and examples}

First, case studies are interdisciplinary, have broad appeal, and make personal connections to students. For instance, case studies can be used to teach foundational principles and problem-solving strategies of physics, conceptual physics, multiple courses in STEM, and engineering ethics. Case studies can serve as technologically challenging capstone projects, modules in advanced laboratory courses, and the basis of independent studies. Additionally, students may one day encounter case studies if they pursue careers in medicine, law, or business-fields in which case studies are commonly used. With this in mind, we wanted our first module to convey the message that case studies have an interdisciplinary appeal with a unique ability to make direct connections to students' lives. Since our PSTs were more disposed to a liberal arts focus, we chose to reexamine an event that showcases the application of physics to the world of sports and brings local news directly into our classroom. 


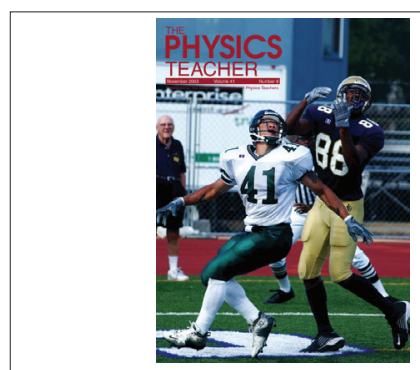

Monday Night Football: Physics Decides Controversial Call" ${ }^{7}$

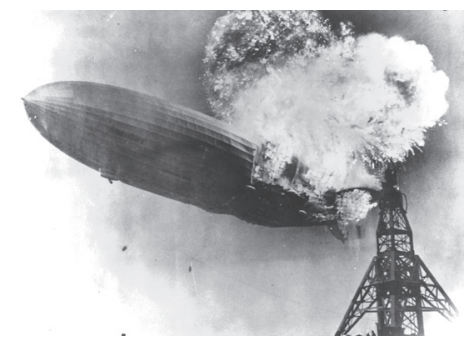

"The Hindenburg Disaster: Combining Physics and History in the Laboratory" 9

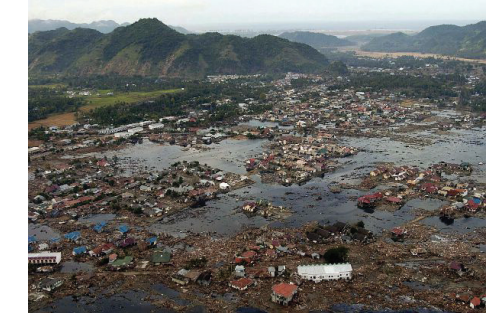

"Modeling the 2004 Tsunami for Introductory Physics Courses" 11

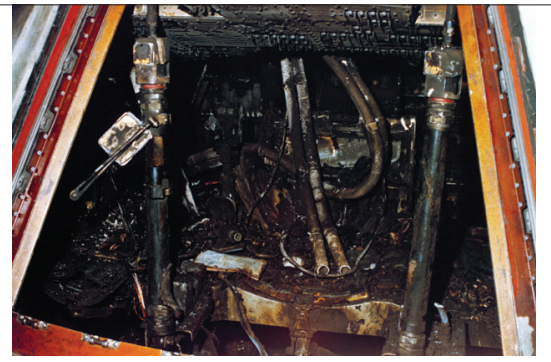

"The Apollo 1 Fire: A Case Study in the Flammability of Fabrics" 8

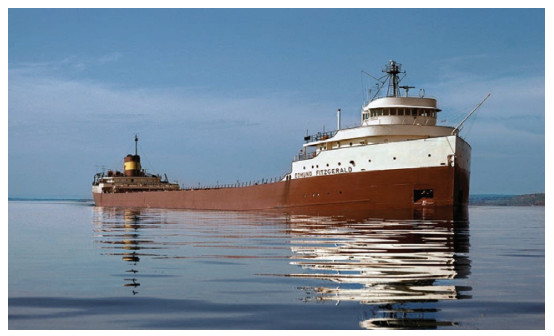

"Remembering the S.S. Edmund Fitzgerald" 10

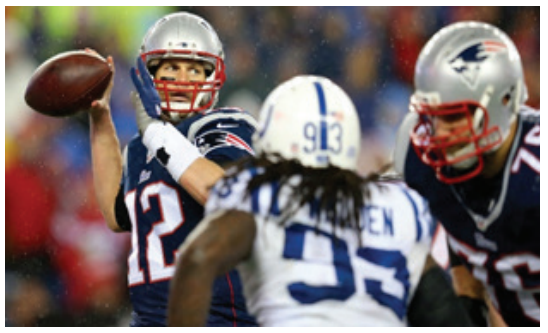

"Bouncing Back from Deflategate" 12

Fig. 1. Our prior TPT articles were assembled into modules that introduce future teachers to the use of case studies as a pedagogy for teaching concepts of physics, problem solving, and critical thinking.

Therefore, we revisited a well-known controversial football play between two Cleveland-area high school football powerhouses. The play is legendary in Cleveland lore and was the subject of our prior TPT article. ${ }^{7}$ In the play, the quarterback for St. Ignatius High School completes a remarkable 90-yard touchdown pass to defeat crosstown rival St. Edwards High School. However, a referee rules that the quarterback had crossed the line of scrimmage as he released the ball, thus negating the victory. A video analysis of the play suggests that the referee made an incorrect call. Most of the PSTs in class know these high schools so the example, as one respondent commented, "brought physics directly into our lives." The case study certainly served its purpose of personalizing the modules to our PSTs while emphasizing how case studies can be used to bring a wide range of events into the classroom. To our PSTs, we present the historical debate as: "You make the call!" and ask them to determine if the referee indeed made the correct ruling. In laboratory, PSTs examine the play using video analysis software and "tackle" the debate using techniques of basic vector analysis.

Second, case studies, more so than traditional pedagogies, raise historical awareness in students. By presenting students with relevant background information, comparative timelines, and leading theories as to why events unfolded as they did, we can bring sometimes forgotten events to new generations of students. For this topic, a new case study was designed to honor the crew of Apollo $1 .^{8}$ On January 27, 1967, a fire swept through the interior of NASA's "AS-204" Command Module and killed American astronauts Chaffee, Grissom, and White during a rehearsal of their upcoming space flight. We present the historical debate as: "What was the source of fuel for the Apollo 1 fire?" In laboratory, PSTs conduct a basic horizontal flame test patterned after the procedures used by the Environmental Protection Agency (EPA) to measure the ignitability of solids.

Third, case studies highlight the importance of operational definitions in scientific experiments. With a case study, students see, perhaps for the first time, how operational definitions compare phenomena of interest against known standards or accepted protocols. Our 2017 TPT article on the Hindenburg disaster provides an excellent case study to illustrate this point. ${ }^{9}$ On May 6, 1937, the German zeppelin Hindenburg caught fire while preparing to dock at the Naval Air Station in Lakehurst, NJ. The ensuing fire destroyed the massive airship in 35 seconds. We present the historical debate as: "What was the source of fuel for the fire that destroyed the Hindenburg?" In laboratory, PSTs piggyback on the horizontal flame test conducted earlier but now conduct a vertical one. This test is patterned after the procedure used by the American Society for Testing and Materials (ASTM) for determining the flammability of textiles. The purpose of both flame tests is to not only raise the historical awareness of the PSTs, but to acclimate them to the idea of adhering to standardized scientific protocols.

Next, case studies demonstrate the "perfect storm scenario" - how a progression of events often results in an unlikely or unforeseen outcome. Our TPT article on the sinking of the S.S. Edmund Fitzgerald provides the basis of this case study. ${ }^{10}$ On November 10, 1975, the Great Lakes bulk cargo freighter S.S. Edmund Fitzgerald suddenly and mysteriously sank during a winter storm on Lake Superior. All 29 men onboard perished. First, since several of the deceased crew members were from Northeast Ohio (some residing only a few miles from campus), the case study once again personalized the modules to our PSTs. As one PST noted about one of the sailors, "Growing up, I had heard his name and seen his picture. I never understood what happened to him or why people remembered him." Next, our laboratory 
activity was designed under the hypothesis that the Fitzgerald sank after encountering a series of rogue waves. Students see that an unlikely cascade of conditions (i.e., the "perfect storm scenario") were met, thus placing the ship at the wrong place at the wrong time. We present the historical debate as: "Why did the S.S. Edmund Fitzgerald sink in Lake Superior on November 10, 1975?" In laboratory, PSTs explore the principle of superposition and use computer simulations to create the conditions that generate rogue waves.

Next, case studies showcase that scientists and engineers must often develop simulations or test analog materials in lieu of actual substances_especially if those substances are prohibitively rare, precious, expensive, or dangerous to test. We use our TPT article that examined the conditions of the Indian Ocean tsunami following the Sumatra-Andaman earthquake of December 26, 2004. ${ }^{11}$ As a result of the earthquake, a $1200 \mathrm{~km} \times 900 \mathrm{~km}$ area of the ocean floor slipped 15 vertical meters where the Indo-Australian plate subducts under the smaller overriding Burma microplate. The ensuing tsunami led to the deaths of more than 200,000 people and devastated parts of Indonesia, Sri Lanka, India, Thailand, Somalia, and Burma. We designed our case study so that the PSTs simulate the event using water tanks. We present the historical debate as: "What factors contributed to the formation of the Indian Ocean tsunami of 2004?" In laboratory, PSTs use the water tanks, basic wave equations, and the principle of conservation of energy to determine the factors affecting the shape and propagation of waves as they reach shore.

Last, case studies allow teachers to emphasize that scientists now take a forensics approach to historical events. Scientists no longer adopt a strictly passive approach to history. Instead, they bring sophisticated analytical tools to scrutinize why certain events happened. Far from being a set of agreed upon immutable facts, the historical record is open to reexamination and reinterpretation. The $2015 \mathrm{AFC}$ Championship game between the New England Patriots and the Indianapolis Colts, better known as "Deflategate," was the subject of our 2015 TPT article and serves as a conclusion to our series of modules. ${ }^{12}$ At halftime of this game, officials determined that 11 of the 12 footballs being used by the Patriots on offense were significantly underinflated. The team was immediately accused of intentionally using underinflated balls to give its offense an advantage. We present the historical debate as: "Did the New England Patriots cheat during the AFC Championship game of 2015?” In laboratory, PSTs analyze sound waves from various professional-grade sports balls as they bounce off of the floor. Although the laboratory activity could focus on topics such as the ideal gas law, projectile motion, conservation of energy, or linear impulse/momentum, we simply use the opportunity to emphasize measurement in laboratory activities.

\section{Reactions from pre-service teachers}

Eighteen pre-service teachers reflected on how they might use a case study pedagogy to plan and implement their own instruction. Overall, the PSTs welcomed the opportunity to incorporate case studies into their repertoire of teaching ped- agogies. According to the PSTs, the approach is an effective way for learners to contextualize physics in real-world situations that are more engaging, relevant, and exploratory than what are commonly found in more traditional teaching pedagogies. Of universal appeal to the PSTs was the open-ended nature of case studies (i.e., that each controversy had no correct "textbook" solution). For example, one PST commented: "My students will enjoy being 'detectives' and 'MythBusters,' trying to unravel why certain events happened. I know I did when I was trying to figure out the case studies we examined. I really wanted to solve each of the mysteries we explored." Another PST commented that the case studies were so interesting and puzzling that she "couldn't wait to get into lab and figure out an explanation of what might have happened."

Feedback from PSTs reveals four specific themes regarding their perceptions of the strengths associated with using a case study-based pedagogy: First, to our surprise, half of the PSTs identified our previous TPT articles and publications in other peer-reviewed journals as a powerful motivating influence for learning content. PSTs commented that seeing their instructors engaged in sustained research into these events was a strong motivation to learn the material themselves. One PST commented: "I was excited to see my professor so engaged and personally interested in the case studies." Another PST remarked: "Seeing our professors doing research outside of the classroom allowed me to view them as researchers who are passionate about their work. These topics are more than just abstract concepts to them. I enjoyed seeing my professors personally invested in the case studies. This motivated me to learn more about the topics myself." Second, discussing the specifics of each case study affirmed our notion that the modules were raising the historical awareness of our PSTs. Prior to class, not one PST was aware of the Apollo 1 fire, the Hindenburg disaster, nor the sinking of the S.S. Edmund Fitzgerald. These events were regarded as "occurring in the distant past" (defined by one PST as any event occurring before 1990), yet were made more relevant to PSTs' lives because of the background information provided. For example, learning about the lives of the three astronauts aboard Apollo 1 made the events more personal and, as one PST noted, "narrowed the gap between 1967 and today." Likewise, one PST remarked about the Hindenburg disaster: "Seeing the newsreel footage and hearing actual audio clips were intense experiences. I realize I have to pay more attention to events that happened outside of my own lifetime. I now understand the significance of the phrase, 'Oh, the humanity!'” (In class, we described Herbert Morrison's eyewitness account of the Hindenburg disaster and phrase "Oh, the humanity!" as legendary audio history.) Third, as much as PSTs appreciated learning about events from the "distant past," they all agreed that analyzing local events, as well as events occurring during their lifetimes, was a strength. Reexamining a well-known local football controversy and learning about local crewmen who perished aboard the Fitzgerald certainly "brought events closer to campus ... and home." Events like "Deflategate" and the Indian Ocean tsunami sparked many discussions among PSTs about where they were when these events occurred and what they remembered 
about each. The take-home message here is that assembling a mix of case studies from local, national, and international events, as well as the recent and distant past, serves as a powerful catalog of situations that appeals to a wide range of students' interests. Finally, PSTs identified the progression of case studies, along with the ability of the instructors to transition from one study to the next, as strengths. Starting the modules with a local event hooked PSTs into the pedagogy. Reexamining back-to-back case studies involving the propagation of flames, followed by back-to-back case studies involving simulations, were perceived as careful course planning on the part of the instructors. Concluding the modules with "Deflategate," which was seen as bringing the experience full circle back to its introductory football activity, provided a sense of closure for the PSTs. "I liked how each topic seemed to be a spin-off of the previous topic. This was a great way to reinforce the previous week's materials and allowed me to make connections between each topic."

Feedback also reveals that the PSTs perceived one major limitation with using case studies in their classrooms-time. Eight respondents commented that although they enjoyed the historical nature of case studies, the pedagogy was perhaps an inefficient use of time and would prevent them from covering necessary content in their classrooms. They felt case studies were simply too time consuming to be used on a regular basis. These respondents commented that case studies are "good for depth, but not for breadth," adding that, "the advantage of case studies is that they allow teachers to dig deeply into topics ... but unfortunately, less topics get covered." To these PSTs, traditional pedagogies like direct instruction or backward design provided more effective means of delivering classroom instruction. One PST noted: "Maybe a case study could be used once or twice a month to add some context to certain topics, but overall, I have to cover more material in class than a case study-approach would allow." Unfortunately, the realities of high stakes testing and pressures from districts and administrators was never far from the minds of the PST: "We simply have to get through a fixed curriculum so that our students have covered the necessary material when testing dates arrive."

Finally, PSTs unanimously appreciated investigating case studies firsthand and encouraged other teacher preparation programs to institutionalize the pedagogy as part of their methods classes or student-teaching experiences. Several PSTs mentioned that whether or not they see themselves using a case studies approach to teaching physics or STEM, they appreciated learning about it and, more importantly, experiencing it. "There are pros and cons to every pedagogical approach and it's up to the teachers to decide what works for them, their students, and their classrooms. Adding the case study approach to my arsenal of delivery methods gives me another choice of how I can teach STEM to my students."

\section{Acknowledgments}

The authors acknowledge the reviewers of this manuscript as well as the reviewers of our prior publications. The work of the reviewers significantly strengthened the presentation of this work.

\section{References}

1. The National Center for Case Study Teaching in Science, University at Buffalo, http://sciencecases.lib.buffalo.edu/cs/. Accessed on June 19, 2018.

2. C. F. Herreid and N. A. Schiller, "Case studies and the flipped classroom,” J. Coll. Sci. Teach. 42 (5), 62-66 (May/June, 2013).

3. T. F. Slater, "Teaching astronomy with case studies," Phys. Teach. 53, 506-507 (Nov. 2015).

4. A. Yadav, M. Lundeberg, M. DeSchryver, and K. Dirkin, "Teaching science with case studies: A national survey of faculty perceptions of the benefits and challenges of using cases," $J$. Coll. Sci. Teach. 37 (1), 34-38 (2007).

5. The Joint Task Force on Undergraduate Physics Programs, "Phys21: Preparing physics students for 21st century careers," (American Physical Society and the American Association of Physics Teachers), https://www.aps.org/programs/education/ undergrad/jtupp.cfm. Accessed on June 27, 2018.

6. D. M. Katz, "Using cases in introductory physics," Forum on Education (American Physical Society, Summer 2009), https:// www.aps.org/units/fed/newsletters/summer2009/katz.cfm. Accessed on June 5, 2018.

7. G. A. DiLisi and R. Rarick, "Monday night football: Physics decides controversial call," Phys. Teach. 41, 454-459 (Nov. 2003).

8. G.A. DiLisi and S. McLean, "The Apollo 1 fire: A case study in the flammability of fabrics," Phys. Teach. 57, 236-239 (April 2019).

9. G. A. DiLisi, “The Hindenburg disaster: Combining physics and history in the laboratory," Phys. Teach. 55, 268-273 (May 2017).

10. G. A. DiLisi and R. A. Rarick, "Remembering the S.S. Edmund Fitzgerald," Phys. Teach. 53, 521-525 (Dec. 2015).

11. G. A. DiLisi and R. A. Rarick, "Modeling the 2004 tsunami for introductory physics Courses," Phys. Teach. 44, 585-588 (Dec. 2006).

12. G. A. DiLisi and R. A. Rarick, "Bouncing back from 'Deflategate," Phys. Teach. 53, 341-346 (Sept. 2015). 